Article

\title{
Synthesis of Single-Phase Zeolite A by Coal Gasification Fine Slag from Ningdong and Its Application as a High-Efficiency Adsorbent for $\mathrm{Cu}^{2+}$ and $\mathrm{Pb}^{2+}$ in Simulated Waste Water
}

\author{
Wenxin Ji ${ }^{1,2}{ }^{2}$, Ning Feng ${ }^{1}$, Pengde Zhao ${ }^{1}$, Shiyue Zhang ${ }^{1}$, Shasha Zhang ${ }^{2}$, Liping Lan ${ }^{2}$, \\ Honglan Huang ${ }^{1}$, Kangning $\mathrm{Li}^{1}$, Yonggang Sun ${ }^{1,2}$, Yuanyuan $\mathrm{Li}^{1,2}$ and Yulong $\mathrm{Ma}^{2}$ \\ 1 State Key Laboratory of High-Efficiency Utilization of Coal and Green Chemical Engineering, \\ Ningxia University, Yinchuan 750021, China; FN13579@126.com (N.F.); zzpd000@163.com (P.Z.); \\ 18395275252@139.com (S.Z.); hhl329846592@126.com (H.H.); 1690243427@163.com (K.L.); \\ ygsun@nxu.edu.cn (Y.S.); liyy@nxu.edu.cn (Y.L.) \\ 2 College of Chemistry and Chemical Engineering, Ningxia University, Yinchuan 750021, China; \\ zssycdi@163.com (S.Z.); 18408610963@189.cn (L.L.); yulongma796@sohu.com (Y.M.) \\ * Correspondence: jwx@nxu.edu.cn; Tel.: +86-135-1957-9989
}

Received: 21 September 2020; Accepted: 3 December 2020; Published: 11 December 2020

\begin{abstract}
Coal gasification is a new direction for the clean utilization of coal, but it also brings huge environmental pressure on solid waste. In this paper, the high-crystallinity single-phase zeolite A was prepared by solid-phase alkali fusion synthesis from coal gasification fine slag (CGFS), without template agent, with low water consumption, and with low cost, and it was used to remove heavy metals such as $\mathrm{Pb}^{2+}$ and $\mathrm{Cu}^{2+}$ in simulated waste water. The main factors affecting the solid-phase and green synthesis methods were analyzed, and the optimum conditions for solid-phase synthesis of high-crystallinity single-phase zeolite A were determined as follows: $\mathrm{NaOH} / \mathrm{CGFS}=1.2$; solid-phase alkali fusion temperature $823 \mathrm{~K}$, solid-phase alkali fusion $90 \mathrm{~min}$, liquid-solid ratio 4.5, and $353 \mathrm{~K}$ hydrothermal reaction for $12 \mathrm{~h}$. The relative crystallinity, specific surface area, and ion-exchange capacity of single-phase zeolites A are $93.1 \%, 61.09 \mathrm{~m}^{2} / \mathrm{g}$, and $268.4 \mathrm{mmol} / 100 \mathrm{~g}$. The removal rates of $\mathrm{Pb}^{2+}$ and $\mathrm{Cu}^{2+}$ can reach more than $99 \%$, especially for the removal efficiency of $\mathrm{Pb}^{2+}$, which is common in simulated waste water. This is an effective method with important application prospects, and it formed an effective way to recycle solid waste of coal chemical industry.
\end{abstract}

Keywords: coal gasification fine slag; solid alkali fusion; single-phase; zeolite A

\section{Introduction}

Ningdong Coal and Chemical Base in China has the largest single capacity coal gasification plant in the world. With the continuous increase of its production capacity and great environmental pressure, the annual output of Coal gasification slag is close to 10 million tons, of which fine slag accounts for about $50 \%$. Due to the high carbon content of fine slag $(20 \leq 30 \%)$, it cannot be used as building materials [1-4]. Coal Gasified slag has a chemical composition similar to that of zeolites, and if it can be converted at a low cost, it will have great economic and environmental benefits. Coal gasification fine slag can be used in the fields of adsorption of heavy metal pollution, sewage treatment, catalysis, and so on. At the same time, it can reduce environmental pollution and realize the resource utilization of waste and the realization of "Using waste treat waste" [5,6].

Although there are many studies on the preparation of microporous materials with fly ash [7-13], fine slag of coal gasification in Ningdong is produced in the reducing atmosphere $\left(\mathrm{CO}\right.$ and $\left.\mathrm{H}_{2}\right)$ at 
$1400-1500^{\circ} \mathrm{C}$, and obtained after washing gas, flocculation, and filtration. Not only its composition and structure but also its structure and system utilization are different from fly ash [14-16]. No technology can be directly used. At present, the comprehensive utilization of coal gasification slag is seldom studied, and the preparation of zeolite from coal gasification slag is rarely reported. For the utilization of solid waste, the method that is of low cost, with little secondary pollution, and of simple operation should be chosen; otherwise, it is difficult to realize the application [14-16]. In this paper, the solid phase synthesis method is used to synthesize microporous materials from fine slag of coal gasification. The method has the advantages of low cost, simple operation, low water consumption, and low secondary pollution. At the same time, it can also improve the performance of zeolites as a stable ion exchanger, and the products are usually composed of zeolites with high crystallization and a single phase. In that coal gasification fine slag, $\mathrm{Si}$ and $\mathrm{Al}$ occupy a high proportion in the quartz and mullite crystal phase and are difficult to be dissolved in water; the dissolution of the Si and Al components plays a critical role in the nucleation and crystallization of the zeolite [6,17-21].

Zeolite A is a widely used synthetic zeolite and is widely used in sewage treatment and purification [20]. As we all know, the application of zeolite in the removal of heavy metals in sewage has important application prospects, but its synthetic raw materials are often expensive and require expensive template agents. The method is complex, the water consumption is huge, and it causes serious secondary pollution. This kind of zeolite prepared with natural low cost and even solid waste will show greater application prospects. Heavy metal pollution has become one of the most serious environmental problems, and if the coal gasification slag is synthesized into zeolite and applied to the treatment of heavy metal ions in simulated waste water, the purpose of "using waste to treat waste" and resource utilization, it will be beneficial to the environment.

In this paper, the solid phase of coal gasification fine slag was used to synthesize high-crystallinity single-phase zeolite A. Through the comparative experiment of the synthesis conditions, XRD, SEM, $\mathrm{BET}$, and other in situ techniques were used to characterize the synthesis products, and the main factors influencing the solid phase and oligosaprobic methods were analyzed. Given the characteristics of coal gasification fine slag, a template-free, low-cost, easy-to-use solid-phase alkaline fusion synthesis method is proposed, which has good application prospects. The prepared high-crystallinity single-phase zeolites A has a good effect on the treatment of heavy $\mathrm{Pb}^{2+}, \mathrm{Cu}^{2+}$ in simulated waste water, especially for $\mathrm{Pb}^{2+}$ with better selectivity. The solid-phase alkali fusion synthesis of coal gasification fine slag into high-crystallinity single-phase zeolite A. This study provides a new idea for solving the large-scale accumulation of coal gasification fine slag (CGFS) and the treatment of ammonia nitrogen and heavy metals, especially $\mathrm{Pb}^{2+}$ and $\mathrm{Cu}^{2+}$, in industrial-simulated waste water. This is a very promising green environmental protection and "waste control waste" route.

\section{Experimental Section}

\subsection{Materials and Reagents}

We used coal gasification fine slag (CGFS) from Ningdong Coal Chemical Base of China as the raw material for the synthesis of zeolites. The fine slag of coal gasification was dried at $378 \mathrm{~K}$ in a constant temperature drying box for $24 \mathrm{~h}$ and preserved after grinding. The sodium hydroxide particles were used as alkaline activating agent, the silicon and aluminum in the coal gasification slag are activated, and the sodium aluminate $\left(\mathrm{NaAlO}_{2}\right)$ was used as aluminum source. The ratio of silicon to aluminum $\left(\mathrm{SiO}_{2} / \mathrm{Al}_{2} \mathrm{O}_{3} \approx 1\right)$ in the reaction mixture was adjusted to prepare the target molecular sieves. Pure lead nitrate and copper nitrate were analyzed as raw materials for simulating different heavy metal ions in simulated waste water.

\subsection{Zeolite A Synthesis}

$3.5 \mathrm{~g}$ dried fine coal gasification slag samples were weighed in a mortar, and $4.2 \mathrm{~g} \mathrm{NaOH}$ was added according to $\mathrm{NaOH} / \mathrm{CGFS}=1.2$ to grind for $10 \mathrm{~min}$ and then put into a nickel vessel. Solid-state 
was melted for 90 min at $823 \mathrm{~K}$ in muff furnace before cooling. $\mathrm{NaAlO}_{2}$ was added to the product after fusion to adjust the ratio $\left(\mathrm{SiO}_{2} / \mathrm{Al}_{2} \mathrm{O}_{3} \approx 1\right)$ of the mixture. After grinding the mixture for $5 \mathrm{~min}$, the mixture was transferred to $100 \mathrm{~mL}$ Teflon liner and deionized water (liquid-solid ratio, 4.5 5.5) was added for full stirring. The mixture was put into a hydrothermal reaction kettle and kept the constant temperature in a thermostatic drying box $353 \mathrm{~K}$ for $12 \mathrm{~h}$. After cooling at the end of reaction time, the product was washed and filtered to a $\mathrm{pH}$ of about 10 . The solid product after filtration was dried overnight at $378 \mathrm{~K}$. The process flow chart is shown in Figure 1.The reaction chemical equation is as follows:

$$
\begin{gathered}
(2 \mathrm{x}+2 \mathrm{y}) \mathrm{NaOH}+\mathrm{xAl}_{2} \mathrm{O}_{3} \cdot \mathrm{ySiO} 2 \stackrel{\text { fusion }}{\rightarrow} \mathrm{yNa}_{2} \mathrm{SiO}_{3}+2 \mathrm{xNaAlO}_{2}+(\mathrm{y}+\mathrm{x}) \mathrm{H}_{2} \mathrm{O} \\
12 \mathrm{Na}_{2} \mathrm{SiO}_{3}+12 \mathrm{NaAlO}_{2}+39 \mathrm{H}_{2} \mathrm{O} \rightarrow \mathrm{Na}_{12} \mathrm{Al}_{12} \mathrm{Si}_{12} \mathrm{O}_{48} \cdot 27 \mathrm{H}_{2} \mathrm{O}+24 \mathrm{NaOH}
\end{gathered}
$$

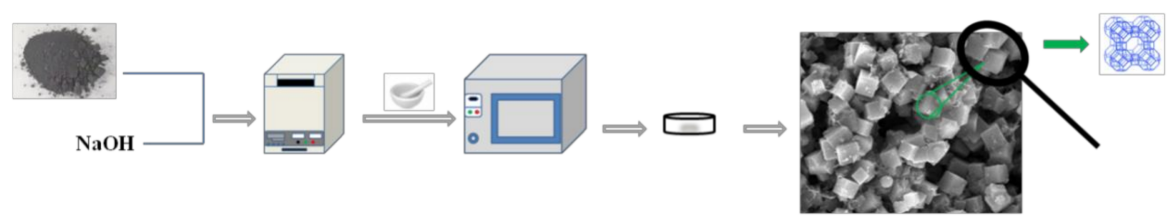

Figure 1. Flow chart of single-phase A zeolite synthesis.

\subsection{Heavy Metal Treatment Experiment}

$15,985 \mathrm{~g}$ and 37,750 $\mathrm{g}$ of analytically pure lead nitrate and copper nitrate were weighed in a beaker, respectively, and added to deionized water, and stirred until completely dissolved. The mixture was placed in a volumetric flask with a constant volume of $1000 \mathrm{~mL}$. Heavy metal ion reserve solution with a concentration of $1000 \mathrm{mg} / \mathrm{L}$ was prepared, and heavy metal simulated waste water with different concentrations was simulated according to different experimental requirements.

Simulation of $100 \mathrm{mg} / \mathrm{L} \mathrm{Pb}\left(\mathrm{NO}_{3}\right)_{2}, \mathrm{Cu}\left(\mathrm{NO}_{3}\right)_{2}$ heavy metal simulated waste water $100 \mathrm{~mL}$ in a conical flask, add $1.5 \mathrm{~g}$ of heavy metal adsorbent, adjust $\mathrm{pH}=6$ with $2 \% \mathrm{HNO}_{3}$, oscillate in a thermostatic oscillator for $240 \mathrm{~min}$, the rotation speed is $150 \mathrm{r} / \mathrm{min}$. The supernatant was filtered by a glass fiber filter with a pore diameter of 0.45 microns, and the concentration of heavy metal ions in the solution was determined by ICP-MS. Calculation formula of removal rate of heavy metal ions:

$$
\eta(\%)=\frac{C_{0}-C_{t}}{C_{0}} \times 100 \%
$$

\subsection{Characterization Methods}

The concentration of heavy metals in the solution was determined by Thermo Fisher Scientific ICP TQ.

X-ray fluorescence spectroscopy (XRF) used S2 Ranger (Karlsruhe, Baden-Wurttemberg, Germany) spectrometer to study the chemical composition of CGFS. X-ray diffraction (XRD) was carried out on the crystal phase of solid products by D8 advanced diffractometer (Bruker, Karlsruhe, Baden-Wurttemberg, Germany). The working voltage of $\mathrm{CuK} \alpha$ radiation source is $40 \mathrm{kV}$ and $40 \mathrm{~mA}$. The $2 \theta$ range is $5-60^{\circ}$, and the scanning speed is $2^{\circ} / \mathrm{min}$.

The morphology and structure of CGFS were studied with JSM-7500F scanning electron microscope and synthesized zeolite products. The characteristic functional groups on the surface of the zeolite can be analyzed by FTIR. The position of the infrared absorption peak can judge the structure of the functional group and the bond of the material. The silicon-oxygen bond and the aluminum-oxygen bond in the sample have special stretching vibration peaks in the infrared spectrum. This study uses the Fourier transform infrared spectrometer produced by PerkinElmer, USA. Using KBr as the background, the scan was in the range of $400-4000 \mathrm{~cm}^{-1}$. 
ASAP2020 physical adsorption analyzer (Micromeritics, USA) was used to obtain the $\mathrm{N}_{2}$ adsorption-desorption isotherm curve at $77 \mathrm{~K}$. The specific surface area is determined by the BET equation, and the pore size distribution is calculated by the $\mathrm{N}_{2}$-DFT model.

The cation exchange capacity of the sample was determined by Nessler spectrophotometry. The sample to be tested was dried under the condition of $378 \mathrm{~K}$, and the $\mathrm{NH}_{4} \mathrm{Cl}$ standard solution having a concentration of $18.69 \mathrm{mmol} / \mathrm{L}$ was accurately set for use. The sample was uniformly mixed at a liquid-solid ratio of $10 \mathrm{~g} / \mathrm{L}$ and shaken at a constant speed, for $24 \mathrm{~h}$, in a $298 \mathrm{~K}$ constant-temperature shaker. The $\mathrm{NH}^{4+}$ concentration was determined by Nessler spectrophotometry at $420 \mathrm{~nm}$, using an ultraviolet spectrophotometer, and each experiment was repeated three times, in parallel [10]. The formula for calculating the cation exchange capacity is as follows:

$$
C E C=\frac{\left(C_{0}-C_{t}\right) \times V \times 10^{-3}}{m}
$$

In the formula, $\mathrm{C}_{0}$ is the initial concentration of $\mathrm{NH}_{4}{ }^{+}$ions in the solution $(\mathrm{mmol} / \mathrm{L}), C_{t}$ is the concentration of $\mathrm{NH}_{4}{ }^{+}$ion $\mathrm{mmol} / \mathrm{L}$ ) in $\mathrm{t}$ moment solution, $V$ is the volume of solution (L), and $m$ is the mass of zeolite (g).

The relative crystallinity $(D)$ of the solid-phase synthesis product is calculated as follows $[10,12,22,23]$.

$$
D(\%)=\frac{\mathrm{P}}{\mathrm{P}_{\mathrm{S}}} \times 100 \%
$$

In the formula, $\mathrm{P}$ denotes the sum of the areas under the XRD diffraction peaks of zeolites $\mathrm{A}$, and $\mathrm{P}_{\mathrm{S}}$ denotes the total area of the XRD diffraction peaks of the synthesized products.

\section{Results and Discussion}

\subsection{Types and Contents of Substances in Coal Gasification Fine Slag}

The chemical composition of the coal gasification fine slag is shown in Table 1. The total content of coal gasification fine slag $\mathrm{SiO}_{2}(54.5 \%)$ and $\mathrm{Al}_{2} \mathrm{O}_{3}(15.7 \%)$ is over $70 \%$, and the corresponding silicon-aluminum ratio $\left(\mathrm{SiO}_{2}: \mathrm{Al}_{2} \mathrm{O}_{3}\right)$ is about 5 . The XRD pattern of the coal gasification fine slag (Figure 2) shows that the main diffraction peak appears as quartz, and the "tap peak" indicates that most of the coal gasification fine slag exists in a glassy form. Under the condition of NaOH/CGFS = 1.5, the melting temperature of solid phase was $823 \mathrm{~K}$ for $90 \mathrm{~min}$; the XRD pattern of the resulting products showed that the solid phase melting removed the unburned carbon remaining in the fine slag of coal gasification. Because of the action of alkali, the quartz phase was transformed into soluble aluminosilicates such as $\mathrm{NaAlO}_{2}$ and $\mathrm{Na}_{2} \mathrm{SiO}_{3}$, proving that the solid-phase melting could activate the silicon and aluminum in the fine slag of coal gasification.

Table 1. Substance types and contents of coal gasification slag (CGFS).

\begin{tabular}{ccccccccc}
\hline \multicolumn{10}{c}{ Chemical Composition (wt \%) } \\
\hline $\mathrm{SiO}_{2}$ & $\mathrm{Al}_{2} \mathrm{O}_{3}$ & $\mathrm{Na}_{2} \mathrm{O}$ & $\mathrm{Fe}_{2} \mathrm{O}_{3}$ & $\mathrm{MgO}$ & $\mathrm{CaO}$ & $\mathrm{K}_{2} \mathrm{O}$ & $\mathrm{TiO}_{2}$ & Total \\
\hline 54.5 & 15.7 & 1.77 & 7.32 & 2.76 & 10.1 & 3.43 & 1.23 & 96.81 \\
\hline
\end{tabular}

S2 Ranger X-ray fluorescence spectrometer (XRF), using brook AXS, Germany; system flushing with helium, $\mathrm{X}$-ray tube as Pd target, maximum power: 50 max voltage: 50 max current $2 \mathrm{~mA}$. 


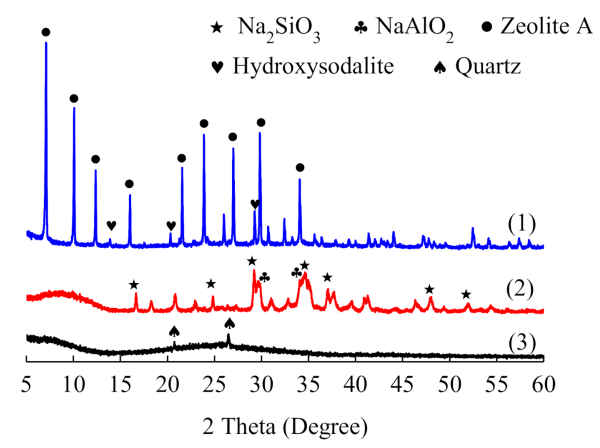

Figure 2. XRD pattern of coal gasification fine slag (CGFS), solid-phase molten product, and synthetic zeolite A. (1) Zeolite A, (2) fusion product, and (3) CGFS.

\subsection{Zeolite Synthesis and Optimization}

\subsubsection{Effect of Solid-Phase Alkali Fusion Temperature}

The activation of coal gasification fine slag is influenced by different solid melt temperature. The $\mathrm{Si}$ and $\mathrm{Al}$ components in the fine slag of coal gasification can be transformed into a large number of silicate and aluminosilicate through high-temperature alkali fusion, increasing the number of minerals and participating in the crystallization of zeolite in the subsequent hydrothermal reaction. An appropriate amount of $\mathrm{Na}^{+}$can achieve the highest degree of crystallization nucleation of activated $\mathrm{Si}$ and $\mathrm{Al}$ and reduce energy and water consumption. Figure 3 is the XRD pattern of zeolite synthesized under different solid-phase alkali melting temperatures. The results show that different solid-phase alkali melting temperatures produce different XRD diffraction peak intensity of the zeolite product; the conversion of quartz phase is not complete at a lower temperature; the product's relative crystallinity is only $30.03 \%$, which may be due to the decrease in the amount of $\mathrm{NaAlO}_{2}$; and $\mathrm{Na}_{2} \mathrm{SiO}_{3}$ generated at lower reaction temperatures and the formation of fewer nuclear sites. With the increase of temperature, the intensity of the zeolite diffraction peak of the product increases, and there is no significant difference between 823 and $873 \mathrm{~K}$. Therefore, $823 \mathrm{~K}$ is the appropriate solid-phase melt-activation temperature.

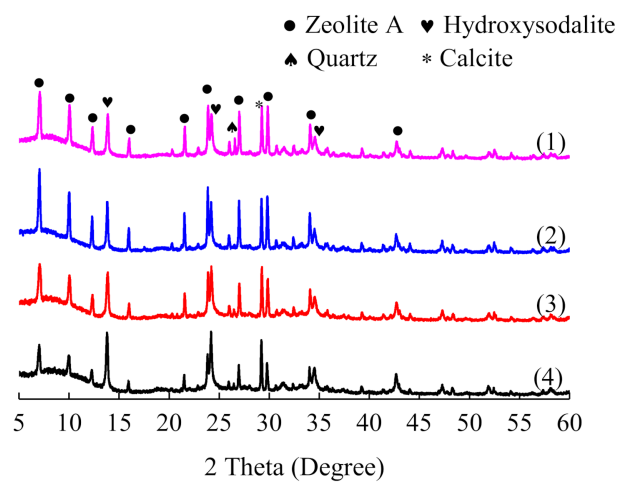

Figure 3. XRD of zeolite A synthesized at different solid-phase alkali fusion temperatures. Reaction conditions: $m(\mathrm{NaOH}) / m(\mathrm{CGFS})=1.2$, liquid/solid ratio $5.5 \mathrm{~mL} / \mathrm{g}$, hydrothermal reaction temperature $373 \mathrm{~K}$, hydrothermal reaction time $12 \mathrm{~h}$. Solid-phase alkali fusion temperature/K: (1) 873, (2) 823, (3) 773, and (4) 673.

\subsubsection{Effect of Hydrothermal Reaction Temperature}

The hydrothermal reaction temperature has a great influence on the purity of the synthesized zeolite. Figure 4 is an XRD pattern of the zeolite synthesized under different hydrothermal reaction temperatures. It can be seen from the figure that the characteristic diffraction peak intensity of zeolite 
A is low at $343 \mathrm{~K}$, and the relative crystallinity is the smallest. Since the hydrothermal reaction is carried out in a closed autoclave when the temperature rises, the dissolution and crystallization rate of the hydrothermal reaction are improved. As the hydrothermal reaction temperature increases again, the intensity of the diffraction peak of the product decreases, and the characteristic diffraction peak of the hydroxides (Hydroxysodalite) is obviously enhanced. Since the sodalite is a relatively stable crystalline phase, the zeolite A phase begins to dissolve, thus indicating that higher temperatures are not conducive to the formation of zeolite A [20,22-24]. At $353 \mathrm{~K}$, the obtained diffraction peak type zeolite sharp and miscellaneous crystals least facilitate the synthesis of high-crystallinity single-phase zeolite A. The temperature is too high or too low, which is not conducive to the formation of zeolite A. In this experiment, $353 \mathrm{~K}$ is selected as the hydrothermal reaction temperature.

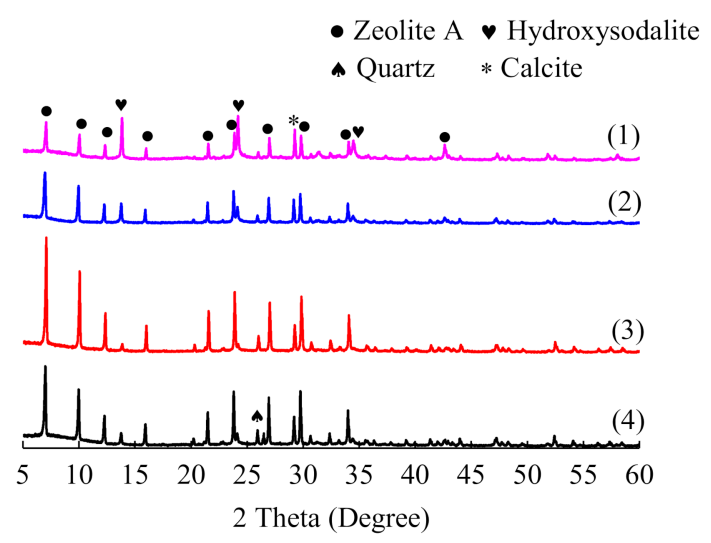

Figure 4. XRD of zeolite A synthesized at different hydrothermal reaction temperatures. Reaction conditions: $m(\mathrm{NaOH}) / m(\mathrm{CGFS})=1.2$; solid-phase alkali fusion temperature, $823 \mathrm{~K}$; liquid/solid ratio, $5.5 \mathrm{~mL} / \mathrm{g}$; and hydrothermal reaction time, $12 \mathrm{~h}$. Hydrothermal reaction temperature/K: (1) $373 \mathrm{~K}$, (2) $363 \mathrm{~K}$, (3) $353 \mathrm{~K}$, and (4) $343 \mathrm{~K}$.

\subsubsection{Effect of $\mathrm{NaOH} / \mathrm{CGFS}$ (Mass Ratio)}

The activation of $\mathrm{Al}$ is an important part of the preparation of zeolite. By fusing the solid phase with the alkaline hydroxide, the Si and Al components in the coal gasification fine slag can be converted into a large amount of silicate and an aluminosilicate, and the quantity of the minerals is increased. These new phases are very soluble in alkaline solutions, to produce high concentrations of silicon and aluminum, which promotes the formation of the zeolite and participates in the crystallization of the zeolite in a subsequent hydrothermal reaction. When the solid-phase sodium hydroxide is melted and activates the coal gasification slag, the crystallization and the nucleation process of the $\mathrm{Na}^{+}$on the synthesis process of the zeolite have a good catalytic effect, and a proper amount of $\mathrm{Na}^{+}$ can enable the activated $\mathrm{Si}$ and $\mathrm{Al}$ to reach the highest degree of crystal nucleation [25]. Moreover, the energy and water resource consumption can be reduced, so that the coal gasification slag solid phase, the green, and the large-scale synthetic zeolite can be made possible. Figure 5 is an XRD pattern of a synthetic zeolite under different $\mathrm{NaOH} / \mathrm{CGFS}$. The reaction mixture forms soluble silicate and aluminate in the solid-phase fusion process, wherein $\mathrm{NaOH}$ acts as an activator, and different $\mathrm{NaOH} / \mathrm{CGFSs}$ affect the activation degree of $\mathrm{Si}$ and $\mathrm{Al}$ in the coal gasification fine slag, thereby affecting the water heat and the crystallinity of the synthetic zeolite. $\mathrm{Na}^{+}$also plays an important role in the zeolitic process and can be used as a sub-structural unit (especially a six-molecular ring) that stabilizes the zeolite framework $[17,18,25]$. The experimental results show that the crystallinity of the synthesized zeolite increases with the increase of the amount of $\mathrm{NaOH}$. When the $\mathrm{NaOH} / \mathrm{CGFS}$ is greater than 1.2 , the crystal of sodalite is gradually formed, and the intensity of the diffraction peak is gradually increased. Therefore, in this experiment, $\mathrm{NaOH} / \mathrm{CGFS}=1.2$ was selected to synthesize zeolite A. 


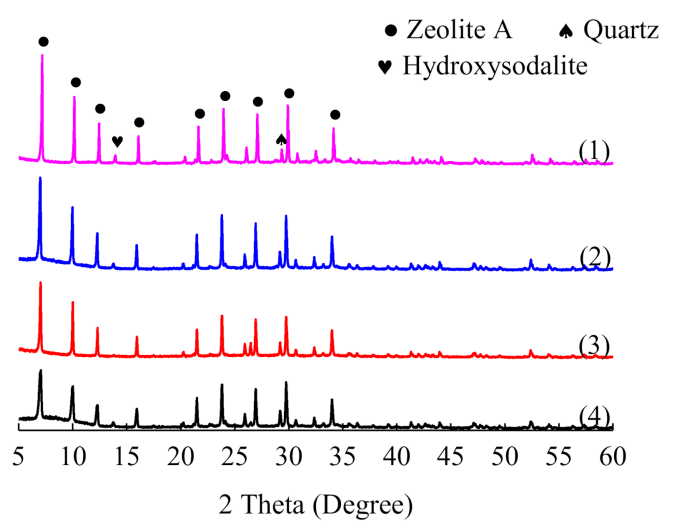

Figure 5. XRD of zeolite A synthesized by different $m(\mathrm{NaOH}) / m(\mathrm{CGFS})$ in solid-phase alkali fusion. Reaction conditions: solid-phase alkali fusion temperature, $823 \mathrm{~K}$; liquid/solid ratio, $5.5 \mathrm{~mL} / \mathrm{g}$; hydrothermal reaction temperature, $353 \mathrm{~K}$; and hydrothermal reaction time, $12 \mathrm{~h} . m(\mathrm{NaOH}) / m(\mathrm{CGFS})$ :

(1) $1: 1.6,(2) 1: 1.5,(3) 1: 1.2$, and (4) $1: 1$.

\subsubsection{Effect of Hydrothermal Synthesis Time}

The hydrothermal synthesis time affects the crystallization of zeolite. Figure 6 shows the XRD pattern of zeolite A synthesized by different hydrothermal synthesis time. The results show that the hydrothermal reaction time is insufficient, the zeolite crystal cannot grow completely, the hydrothermal reaction time is too long, and the cost is increased. At the same time, the zeolite is also converted into other crystals, reducing the crystallinity of the target product. The characteristic diffraction peak of zeolite A occurs when the hydrothermal reaction time is $6 \mathrm{~h}$, but the intensity of the diffraction peak is weak at this time, and the relative crystallinity of the zeolite A is low. As the reaction time increases, the synthesized product is mainly zeolite A, and the intensity of the characteristic diffraction peak is significantly increased, and the peak is less. However, when the reaction time is increased to $24 \mathrm{~h}$, there are obvious characteristic peaks of sodalite in the product, which are the main products. When the reaction time exceeds $24 \mathrm{~h}$, the characteristic diffraction peak of zeolite A disappears, and the crystals are transformed into more Stable sodalite crystal [26]. Therefore, the hydrothermal reaction time of the synthesized zeolite A is preferably $12 \mathrm{~h}$, and the product has the best relative crystallinity.

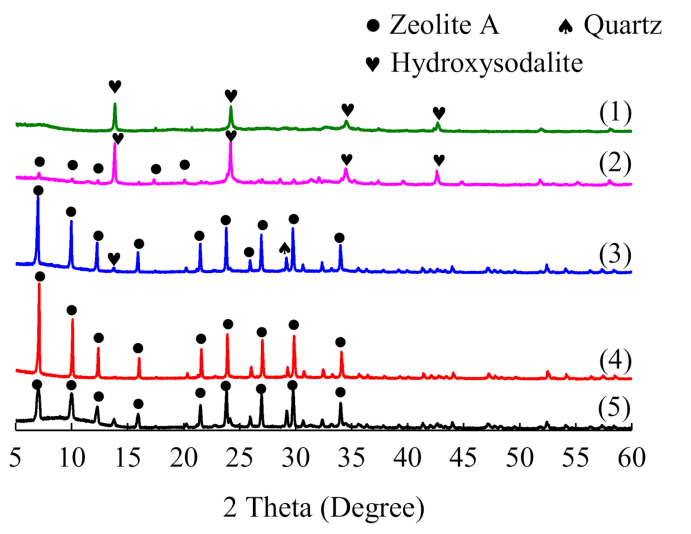

Figure 6. XRD of zeolite A synthesized at different hydrothermal reaction times. Reaction conditions: $m(\mathrm{NaOH}) / m(\mathrm{CGFS})=1.2$; solid-phase alkali fusion temperature, $823 \mathrm{~K}$; liquid/solid ratio, $5.5 \mathrm{~mL} / \mathrm{g}$; and hydrothermal reaction temperature, $353 \mathrm{~K}$. Hydrothermal reaction time/h: (1) $30 \mathrm{~h}$, (2) $24 \mathrm{~h}$, (3) e unify the format betw18 h, (4) $12 \mathrm{~h}$, and (5) $6 \mathrm{~h}$. 


\subsubsection{The Effect of Different Liquid-Solid Ratios}

Adjusting the liquid-solid ratio means water consumption and secondary pollution. After solidphase fusion and activation, to meet the goal of green synthesis, water consumption and energy consumption should be minimized. It is necessary to find a synthetic single phase with less water and higher crystallinity. The condition of zeolite $\mathrm{A}$ is an inevitable requirement for scale production. Figure 7 is an XRD pattern of zeolite A synthesized under different liquid-solid ratios. The results show that, in the hydrothermal reaction process, the zeolite A product is present under the selected liquid-solid ratio synthesis conditions. The difference is that, when the reaction liquid-solid ratio is 2.5 and 3.5, the intensity of the product diffraction peak is low, and there is also a peak of hydroxysodalite, and when the liquid-solid ratio reaches about 5, the characteristics of the type A molecular sieve appear in the product. The peak fits well with the standard card (PDF \#73-2340) and has a better relative crystallinity. Therefore, in this experiment, a liquid-solid ratio of 4.5 synthetic zeolite A was selected.

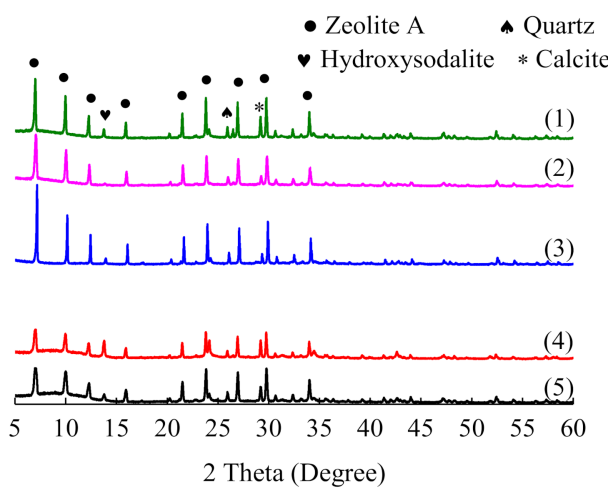

Figure 7. XRD of zeolites A synthesized at different liquid/solid ratios. Reaction conditions: $m(\mathrm{NaOH}) / m(\mathrm{CGFS})=1.2$; solid-phase alkali fusion temperature, $823 \mathrm{~K}$; hydrothermal reaction temperature, $353 \mathrm{~K}$; and hydrothermal reaction time, $12 \mathrm{~h}$. Liquid/solid ratio/(mL.g $\left.{ }^{-1}\right)$ : (1) 6.5, (2) 5.5, (3) 4.5 , (4) 3.5 , and (5) 2.5 .

Through the optimization of the above synthesis conditions, the best conditions for preparing zeolite A using solid-phase alkaline fusion of Ningdong coal gasification fine slag as raw materials are obtained, that is, $m(\mathrm{NaOH}) / m(\mathrm{CGFS})$ is 1.2 , solid-phase alkaline fusion temperature is $823 \mathrm{~K}$, the hydrothermal reaction temperature is $353 \mathrm{~K}$, the hydrothermal reaction time is $12 \mathrm{~h}$, and the liquid/solid ratio is $4.5 \mathrm{~mL} / \mathrm{g}$. The relative crystallinity of the synthetic zeolite A under this condition is calculated to be as high as $93.1 \%$ through the calculation of the relative crystallinity formula. Therefore, the process proposed in our research is not only simple in method but low in cost, and the obtained zeolite product has relatively high crystallinity, which is of great significance to waste recycling.

\subsection{Characterization of Synthetic Zeolites}

\subsubsection{Infrared Spectrum}

The infrared spectrum of type A zeolite $(\mathrm{NaOH} / \mathrm{CGFS}=1.2$, the calcination temperature is $823 \mathrm{~K}$, calcination time is $90 \mathrm{~min}$, the liquid-solid ratio is 4.5 , and the hydrothermal reaction temperature is $353 \mathrm{~K}$, time $12 \mathrm{~h}$ ) is shown in Figure 8. The absorption peaks appearing at 465 and $562 \mathrm{~cm}^{-1}$ are $\mathrm{Al}-\mathrm{O}-\mathrm{Al}$ stretching vibrations, and the absorption peaks appearing at $668 \mathrm{~cm}^{-1}$ are $\mathrm{Si}-\mathrm{O}-\mathrm{Si}$ or Al-O-Si stretching vibrations. The characteristic peak appearing at $1004 \mathrm{~cm}^{-1}$ is $\mathrm{Si}-\mathrm{O}-\mathrm{Si}$ or Al-O-Si asymmetric stretching vibration, and it is strong -OH stretching vibration and $-\mathrm{OH}$ bending vibration at $3422 \mathrm{~cm}^{-1}$ and $1657 \mathrm{~cm}^{-1}$. This is consistent with the XRD results, indicating that the aluminosilicate minerals in the coal gasification fines are converted to specific mineral phases of the zeolite A. The FTIR band was consistent with previous reports, confirming the presence of zeolite A structural unit [26-28]. 


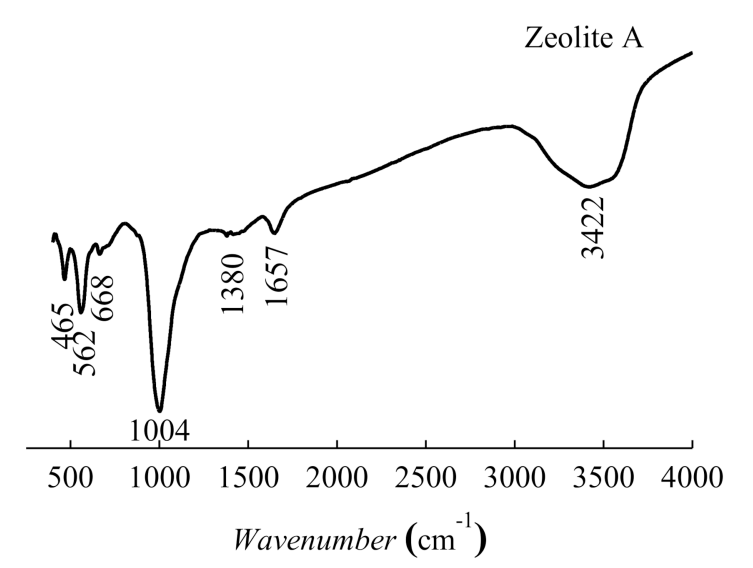

Figure 8. Infrared spectra of zeolite A synthesized by solid-phase alkali fusion.

\subsubsection{Specific Surface Area and SEM}

Figure 9 is a diagram showing the adsorption-desorption curve and the pore size distribution of the solid-phase synthetic zeolite product. The specific surface area and total pore volume of the synthesized product were determined to be $61.1 \mathrm{~m}^{2} / \mathrm{g}$ and $0.09 \mathrm{~cm}^{3} / \mathrm{g}$, and the average adsorption pore diameter was $6.01 \mathrm{~nm}$. Figure 10d is a scanning electron micrograph of the coal gasification fine slag. The results show that the crystal particles range in size from 1.0 to $2.0 \mathrm{um}$, and the spherical particles with a smooth surface and the agglomerated porous glass particles are mainly composed. Scanning electron micrographs (Figure 10a-c) confirmed the special cubic morphology of solid-phase fusion synthesis of single-phase zeolite A. The solid-phase synthesis product zeolite A is mainly composed of regular cubic crystal grains, and the distribution of crystalline products is good, presenting a regular cubic structure and a complete crystal plane. By measuring the ion-exchange capacity, the solid-phase fusion synthesis of high-crystallinity single-phase zeolite A has a CEC (cation exchange capacity) = $268.4 \mathrm{mmol} / 100 \mathrm{~g}$, which has broad application prospects in water purification and ion exchange.

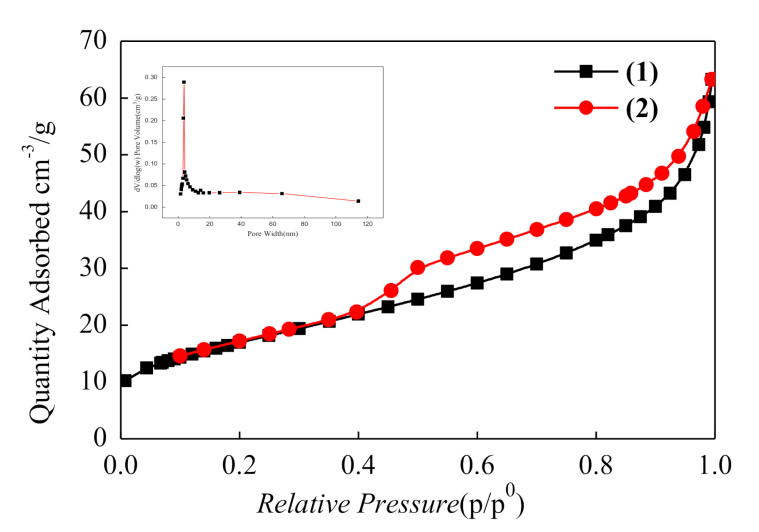

Figure 9. $\mathrm{N}_{2}$ adsorption-desorption curves and pore diameter distribution of zeolite A synthesized by solid-phase alkali fusion. a Adsorption; • desorption. 

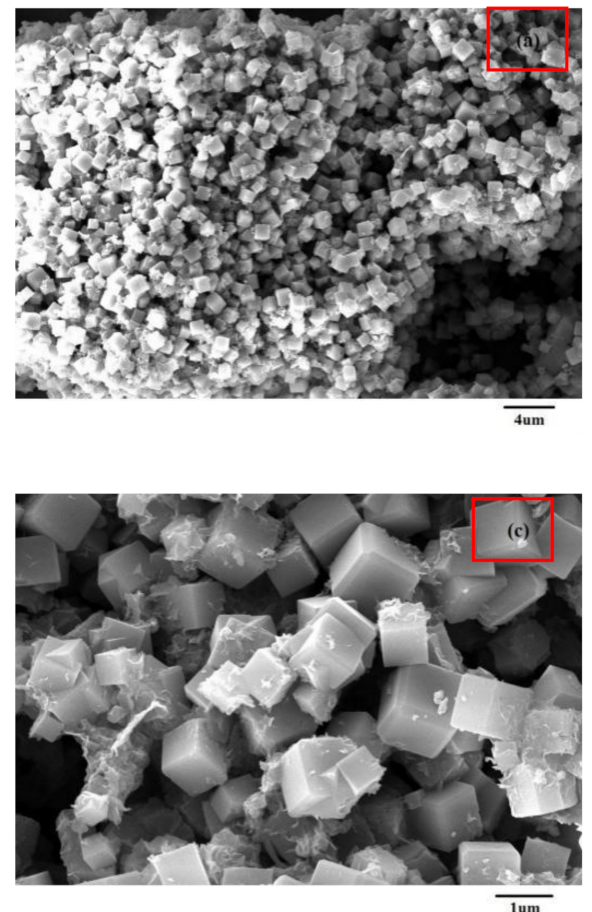
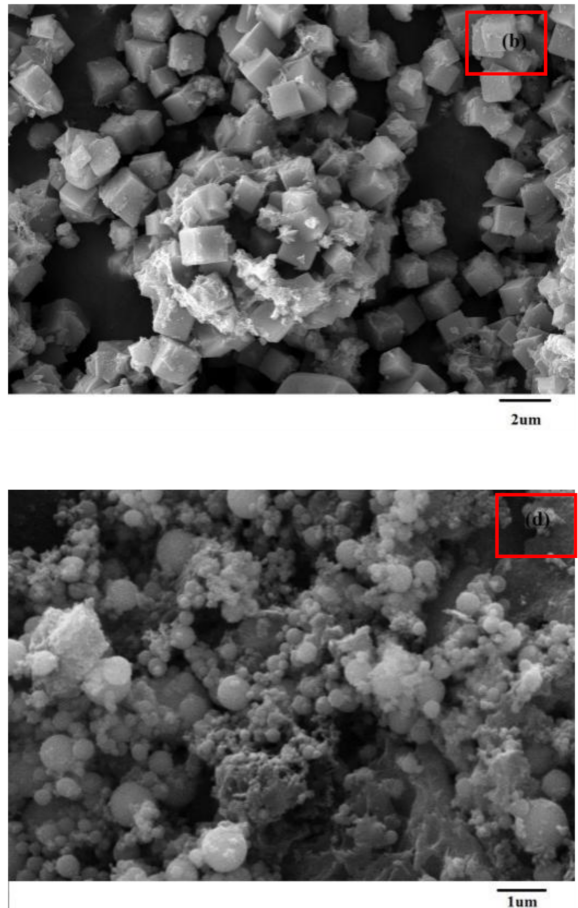

Figure 10. SEM image of fine coal gasification slag and solid-phase synthesis of zeolite. (a-d) are zeolite-A in different magnification.

The high-crystallinity single-phase zeolite prepared by solid-phase alkaline fusion was compared with the synthetic zeolite A reported in the literature (Table 2) [3,8,9]. Due to the high-crystallinity and the pore structure of zeolite A, a large specific surface area is formed, which is beneficial to ion exchange and has a stronger ability to treat heavy metal ions in simulated waste water. Secondly, from the CEC results, it is also higher than the usual results.

Table 2. CEC and specific surface area of synthesized products in different works in the literature.

\begin{tabular}{ccc}
\hline Adsorbent & $\mathbf{C E C} /\left(\mathbf{m m o l} \cdot(\mathbf{1 0 0} \mathbf{~ g})^{\mathbf{- 1}}\right)$ & $S_{\text {BET }} /\left(\mathbf{m}^{\mathbf{2}} \cdot \mathbf{g}^{-\mathbf{1}}\right)$ \\
\hline Zeolite A & 268.4 & 61.10 \\
Zeolite A [9] & 232.2 & 43.70 \\
Zeolite A [8] & 117.7 & 11.41 \\
Zeolite A [8] & 163.1 & 35.55 \\
Zeolite A [8] & 137.6 & 28.74 \\
\hline
\end{tabular}

\subsection{Treatment of Heavy Metal Ions in Simulated Waste Water}

In our research, the high-crystallinity single-phase low-cost A-type zeolite obtained from the resource utilization of coal gasification fine slag can be used for the treatment of heavy metals in industrial simulated waste water. By realizing the on-site transformation of coal gasification slag and "treat waste with waste" concept, we provide a new idea for the treatment of solid waste.

Effects of Adsorbent Dosage, Constant Temperature Oscillation Time, pH Value of the Solution, and Mixed Ions on Removal Rate of Heavy Metal Ions

As shown in Figure 11a, at the same oscillation time, the removal rate of $\mathrm{Cu}^{2+}$ by $0.5 \mathrm{~g}$ of adsorbent was only $53.5 \%$, and the removal rate of $\mathrm{Pb}^{2+}$ was higher, reaching $87.7 \%$. With the increase of adsorbent dosage, the removal rate is increasing. When the amount of adsorbent reaches $1.5 \mathrm{~g}$ or more, the removal rate of the adsorbent for $100 \mathrm{~mL}$ simulated $\mathrm{Cu}^{2+}$ and $\mathrm{Pb}^{2+}$ heavy metal ions can reach more than $99 \%$. 


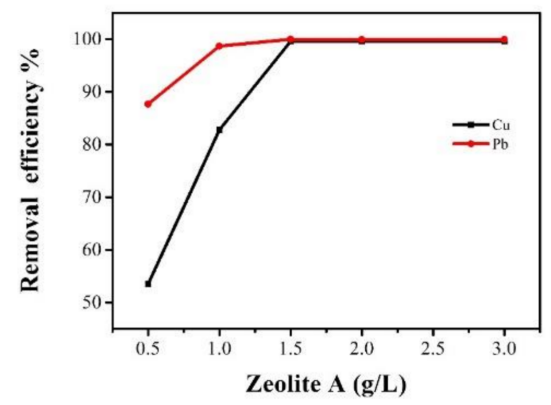

(a)

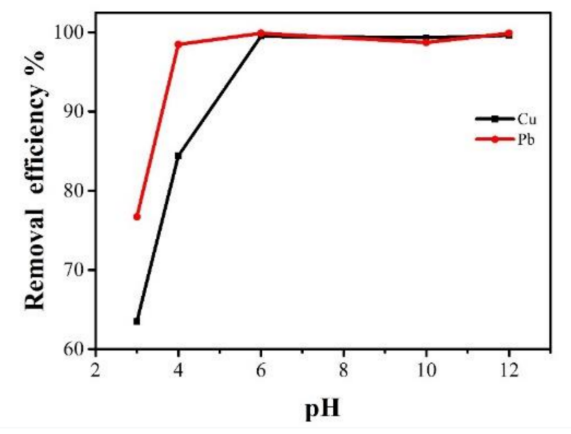

(c)

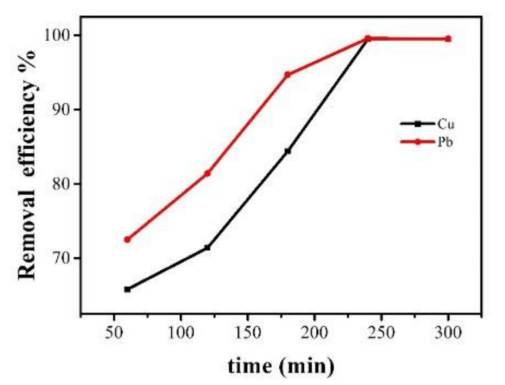

(b)

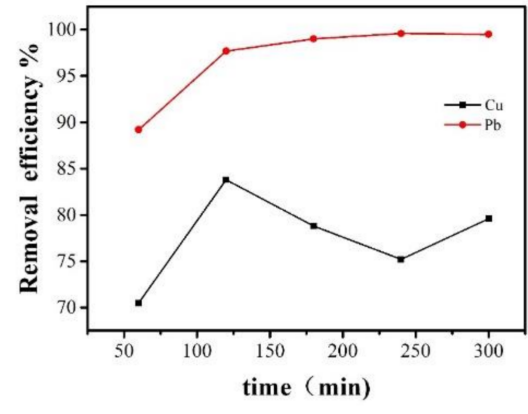

(d)

Figure 11. Effects of different conditions on the removal rate of heavy metal ions. (a-d) are the influence of different influencing factors on experimental results

As shown in Figure 11b, under the low-temperature oscillation time, the removal rates of heavy metal ions are smaller: Heavy metal ions' removal rate increases with the increase of adsorption time, and, when up to $240 \mathrm{~min}$, the removal rate of heavy metal ions can reach above $99 \%$.

This paper explores the removal efficiency of heavy metal ions by adsorbent at different $\mathrm{pH}$ values. As shown in Figure 11c, when $\mathrm{pH}=3$, the removal rates of $\mathrm{Pb}^{2+}$ and $\mathrm{Cu}^{2+}$ were $76.7 \%$ and $63.5 \%$, respectively, due to the competitive effect with $\mathrm{H}^{+}$. With the increase of $\mathrm{pH}$, the removal rate of heavy metal ions increased. When $\mathrm{pH}=6$, the removal rate of heavy metal ions reached more than $99 \%$. While $\mathrm{pH}>10$, heavy metal ions in the solution can form precipitation for removal, and the adsorption effect on the removal of heavy metals is not obvious.

Coexisting ions, especially cations, in the simulated waste water have a great influence on the adsorption effect of zeolite. In the mixed solution of $\mathrm{Pb}^{2+}$ and $\mathrm{Cu}^{2+}$, the removal rate of adsorbent on two kinds of metal ions is shown in Figure 11d. The removal rate of $\mathrm{Pb}^{2+}$ in the solution has little influence, while the removal rate of $\mathrm{Cu}^{2+}$ decreases. This may be because the radius of $\mathrm{Cu}^{2+}$ is much larger than that of $\mathrm{Pb}^{2+}$, while the radius of hydrating ion of $\mathrm{Pb}^{2+}$ is larger than that of $\mathrm{Cu}^{2+}$, so the removal rate of $\mathrm{Pb}^{2+}$ is greater than that of $\mathrm{Cu}^{2+}$ when both ions exist simultaneously. At the same time, the removal rate of $\mathrm{Pb}^{2+}$ is also higher under different adsorbent dosage, different constant temperature oscillation time, and different $\mathrm{pH}$.

The experimental results of the treatment of $\mathrm{Pb}^{2+}$ and $\mathrm{Cu}^{2+}$ heavy metal ions in simulated waste water by the synthesis of high-crystallinity single-phase zeolite A from Ningdong coal gasification fine slag show that removal rates of $\mathrm{Pb}^{2+}$ and $\mathrm{Cu}^{2+}$ can reach more than $99 \%$, especially for the removal of $\mathrm{Pb}^{2+}$ in simulated waste water, which is more harmful to humans. 


\section{Conclusions}

Since the special composition and structure of coal gasification slag cannot be applied to the treatment of fly ash, under the requirement of resource recycling, using coal gasification slag requires a low cost, low water consumption, and a simple process. we have prepared high-crystallinity single-phase zeolite A with CEC $268.4(\mathrm{mmol} / 100 \mathrm{~g})$ and BET $61.1 \mathrm{~m}^{2} / \mathrm{g}$ by using a solid-phase alkali fusion synthesis method without template agent. The optimum conditions for the preparation of high-crystallinity single-phase zeolite A by solid-phase alkali fusion of coal gasification fine slag are as follows: $m(\mathrm{NaOH}) / m(\mathrm{CGFS})=1.2$; solid-phase alkali fusion temperature, $823 \mathrm{~K}$; liquid/solid ratio, $5 \mathrm{~mL} / \mathrm{g}$; hydrothermal reaction temperature, $353 \mathrm{~K}$; and hydrothermal reaction time, $12 \mathrm{~h}$, where $m(\mathrm{NaOH}) / m(\mathrm{CGFS})$ is an important factor affecting the synthesis of single-phase zeolite A. $\mathrm{Na}^{+}$has a good effect on the crystallization and nucleation process in zeolite synthesis. Proper $m(\mathrm{NaOH}) / m(\mathrm{CGFS})$ can make coal gasification fine slag more activated, aluminosilicate better crystallize and nucleate, and consume less energy and water.

We applied the obtained high crystallinity single-phase zeolite $\mathrm{A}$ to the removal of $\mathrm{Pb}^{2+}$ and $\mathrm{Cu}^{2+}$ in simulated waste water, and found that the removal rate of heavy metal $\mathrm{Pb}^{2+}$ and $\mathrm{Cu}^{2+}$ in simulated waste water can reach more than $99 \%$ after the amount of zeolite A material $1.5 \mathrm{~g} / \mathrm{L}$, $\mathrm{pH}=6$, and removal of $250 \mathrm{~min}$. In particular, high-crystallinity single-phase zeolite A prepared from Ningdong coal gasification fine slag has better removal efficiency for the $\mathrm{Pb}^{2+}$ in simulated waste water. This paper points out a promising road for the recycling of coal gasification slag.

Author Contributions: Conceptualization, Y.M.; investigation, W.J.; methodology, W.J.; resources, W.J. and Y.M.; supervision, Y.S. and Y.L.; visualization, S.Z. (Shiyue Zhang) and H.H.; Software, S.Z. (Shasha Zhang); proofreading, L.L.; reading, K.L.; writing—original draft, P.Z. and N.F.; writing—review and editing, W.J. and N.F.; All authors have read and agreed to the published version of the manuscript.

Funding: This research was funded by The National Science Foundation of China (No. 21663019) and The East-West Cooperation Project of Ningxia Key R \& D Plan (2019BFH02014).

Conflicts of Interest: The authors declare that there are no conflicts of interest.

\section{References}

1. Xing, Y.; Guo, F.; Xu, M.; Gui, X.; Li, H.; Li, G.; Xia, Y.; Han, H. Separation of unburned carbon from coal fly ash: A review. Powder Technol. 2019, 353, 372-384. [CrossRef]

2. Hower, J.C.; Groppo, J.G.; Graham, U.M.; Ward, C.R.; Kostova, I.J.; Maroto-Valer, M.M.; Dai, S. Coal-derived unburned carbons in fly ash: A review. Int. J. Coal Geol. 2017, 179, 11-27. [CrossRef]

3. Blissett, R.S.; Rowson, N.A. A review of the multi-component utilization of coal fly ash. Fuel 2012, 97, 1-23. [CrossRef]

4. Gollakota, A.R.K.; Volli, V.; Shu, C.M. Progressive utilization prospects of coal fly ash: A review. Sci. Total Environ. 2019, 672, 951-989. [CrossRef] [PubMed]

5. Höller, H.; Wirsching, U. Zeolite formation from fly ash. Fortschr. Mineral. 1985, 63, 21-43.

6. Shigemoto, N.; Hayashi, H.; Miyaura, K. Selective formation of Na-X zeolite from coal fly ash by fusion with sodium hydroxide prior to hydrothermal reaction. J. Mater. Sci. 1993, 28, 4781-4786. [CrossRef]

7. Molina, A.; Poole, C. A comparative study using two methods to produce zeolites from fly ash. Miner. Eng. 2004, 17, 167-173. [CrossRef]

8. Xie, J.; Wang, Z.; Wu, D.; Zhang, Z.; Kong, H. Synthesis of Zeolite/Aluminum Oxide Hydrate from Coal Fly Ash: A New Type of Adsorbent for Simultaneous Removal of Cationic and Anionic Pollutants. Ind. Eng. Chem. Res. 2013, 52, 14890-14897. [CrossRef]

9. Ren, X.; Xiao, L.; Qu, R.; Liu, S.; Ye, D.; Song, H.-G.; Wu, W.; Zheng, C.; Wu, X.; Gao, X. Synthesis and characterization of a single phase zeolite A using coal fly ash. RSC Adv. 2018, 8, 42200-42209. [CrossRef]

10. Yang, L.; Qian, X.; Yuan, P.; Bai, H.; Miki, T.; Men, F.; Li, H.; Nagasaka, T. Green synthesis of zeolite 4A using fly ash fused with synergism of $\mathrm{NaOH}$ and $\mathrm{Na}_{2} \mathrm{CO}_{3}$. J. Clean. Prod. 2019, 212, 250-260. [CrossRef]

11. Panitchakarn, P.; Laosiripojana, N.; Viriya-Umpikul, N.; Pavasant, P. Synthesis of high-purity Na-A and Na-X zeolite from coal fly ash. J. Air Waste Manag. Assoc. 2014, 64, 586-596. [CrossRef] [PubMed] 
12. Iqbal, A.; Sattar, H.; Haider, R.; Munir, S. Synthesis and characterization of pure phase zeolite 4 A from coal fly ash. J. Clean. Prod. 2019, 219, 258-267. [CrossRef]

13. Shoumkova, A.S.; Stoyanova, V. SEM-EDX and XRD characterization of zeolite NaA, synthesized from rice husk and aluminium scrap by different procedures for preparation of the initial hydrogel. J. Porous Mater. 2012, 20, 249-255. [CrossRef]

14. Tanaka, H.; Fujimoto, S.; Fujii, A.; Hino, A.R.; Kawazoe, T. Microwave Assisted Two-Step Process for Rapid Synthesis of Na-A Zeolite from Coal Fly Ash. Ind. Eng. Chem. Res. 2008, 47, 226-230. [CrossRef]

15. Wu, D.; Lu, Y.; Kong, H.; Ye, A.C.; Jin, X. Synthesis of Zeolite from Thermally Treated Sediment. Ind. Eng. Chem. Res. 2008, 47, 295-302. [CrossRef]

16. EL-Naggar, M.R.; EL-Kamash, A.M.; EL-Dessouky, M.I.; Ghonaim, A.K. Two-step method for preparation of NaA-X zeolite blend from fly ash for removal of cesium ions. J. Hazard. Mater. 2008, 154, 963-972. [CrossRef]

17. Chang, H.-L.; Shih, W.-H. A General Method for the Conversion of Fly Ash into Zeolites as Ion Exchangers for Cesium. Ind. Eng. Chem. Res. 1998, 37, 71-78. [CrossRef]

18. Murayama, N.; Yamamoto, H.; Shibata, J. Mechanism of zeolite synthesis from coal fly ash by alkali hydrothermal reaction. Int. J. Miner. Process. 2002, 64, 1-17. [CrossRef]

19. Belviso, C. State-of-the-art applications of fly ash from coal and biomass: A focus on zeolite synthesis processes and issues. Prog. Energy Combust. Sci. 2018, 65, 109-135. [CrossRef]

20. Ojumu, T.V.; Du Plessis, P.W.; Petrik, L.F. Synthesis of zeolite A from coal fly ash using ultrasonic treatment-A replacement for fusion step. Ultrason. Sonochem. 2016, 31, 342-349. [CrossRef]

21. Ding, L.; Yang, H.; Rahimi, P.; Omotoso, O.; Friesen, W.; Fairbridge, C.; Shi, Y.; Ng, S. Solid transformation of zeolite NaA to sodalite. Microporous Mesoporous Mater. 2010, 130, 303-308. [CrossRef]

22. Reyes, C.A.R.; Williams, C.D.; Alarcón, O.M.C. Nucleation and growth process of sodalite and cancrinite from kaolinite-rich clay under low-temperature hydrothermal conditions. Mater. Res. 2013, 16, 424-438. [CrossRef]

23. Rios, C.A.; Williams, C.D.; Fullen, M.A. Nucleation and growth history of zeolite LTA synthesized from kaolinite by two different methods. Appl. Clay Sci. 2009, 42, 446-454. [CrossRef]

24. Hong, J.L.X.; Maneerung, T.; Koh, S.N.; Kawi, S.; Wang, C.-H. Conversion of Coal Fly Ash into Zeolite Materials: Synthesis and Characterizations, Process Design, and Its Cost-Benefit Analysis. Ind. Eng. Chem. Res. 2017, 56, 11565-11574. [CrossRef]

25. Barnes, M.C.; Addai-Mensah, J.; Gerson, A.R. The mechanism of the sodalite-to-cancrinite phase transformation in synthetic spent Bayer liquor. Microporous Mesoporous Mater. 1999, 31, 287-302. [CrossRef]

26. Purnomo, C.W.; Salim, C.; Hinode, H. Synthesis of pure Na-X and Na-A zeolite from bagasse fly ash. Microporous Mesoporous Mater. 2012, 162, 6-13. [CrossRef]

27. Tanaka, H.; Fujii, A.; Fujimoto, S.; Tanaka, Y. Microwave-Assisted Two-Step Process for the Synthesis of a Single-Phase Na-A Zeolite from Coal Fly Ash. Adv. Powder Technol. 2008, 19, 83-94. [CrossRef]

28. Musyoka, N.M.; Petrik, L.F.; Gitari, W.M.; Balfour, G.; Hums, E. Optimization of hydrothermal synthesis of pure phase zeolite Na-P1 from South African coal fly ashes. J. Environ. Sci. Health Part A 2012, 47, 337-350. [CrossRef] [PubMed]

Publisher's Note: MDPI stays neutral with regard to jurisdictional claims in published maps and institutional affiliations.

(C) 2020 by the authors. Licensee MDPI, Basel, Switzerland. This article is an open access article distributed under the terms and conditions of the Creative Commons Attribution (CC BY) license (http://creativecommons.org/licenses/by/4.0/). 